\title{
APRESENTAÇÃO
}

\section{A DOR E OS SEUS ASPECTOS MULTIDIMENSIONAIS}

\author{
Jaime Olavo Marquez
}

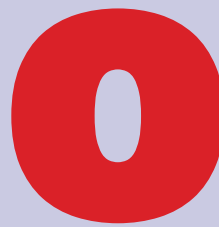

tema a ser abordado no presente Núcleo Temático diz respeito à dor. Serão analisados tópicos referentes apenas às dores crônicas, com atenção ao seu complexo clínico de interações causais, e em um contexto biopsicossocial. Também os aspectos bioéticos, algumas manifestaçôes frequentes, tais como as cefaleias e as lombociatalgias. Quanto ao seu tratamento será feita uma explanação referente à abordagem complementar da acupuntura e de técnicas modernas, conhecidas como técnicas minimamente invasivas, melhor conceituadas no texto pertinente.

\section{OS ASPECTOS MULTIDIMENSIONAIS DAS DORES CRÔNICAS A As-} sociação Internacional para o Estudo da Dor (IASP, International Association for the Study of Pain), conceitua dor como sendo "uma experiência sensitiva e emocional desagradável, associada a uma lesão tecidual atual, potencial, ou descrita em termos de tal lesão". Já McCaffery em uma visão mais humanística, diz que "dor é o que o paciente diz ser, e existe quando ele diz existir”, colocando uma ideia de uma experiência pessoal e peculiar a cada indivíduo. Ferreira F (2004), modificada por Marquez JO (2008), procura uma conceituação mais abrangente, referindo que "dor é a consciência de uma sensação nociceptiva, induzida por estímulos químicos ou físicos, de origem exógena ou endógena, assim como por disfunções psicológicas, tendo como base um mecanismo biopsicossocial, causando emoçôes normalmente desagradáveis, com possibilidades de variáveis graus de comportamentos aversivos".

DORES AGUDAS E DORES CRÔNICAS É importante diferenciar as dores agudas das crônicas. As dores agudas são consideradas fisiológicas, como um sinal de alerta, da maior importância para a sobrevivência. Tem duração limitada no tempo e espaço, cessando com a resolução do processo nóxico.

Já as dores crônicas não têm a finalidade biológica de alerta e sobrevivência e podemos dizer que se constituem como verdadeiramente uma doença. Com relação ao aspecto temporal, as definições variam quanto sua conceituação, da duração de mais de três ou seis meses, ou as que persistem após a cura da lesão inicial. Algumas vezes não se consegue um nexo causal, o que não invalida o seu diagnóstico e sua existência.

As dores crônicas permitem discussōes conceituais da medicina clássica, havendo a necessidade de argumentaçôes que fogem do modelo dito biomédico clássico, com implicaçôes filosóficas, sociais e emocionais, daí o emprego do modelo biopsicossocial. Assim, o pensamento de Shakespeare "Todos são capazes de dominar a dor, exceto quem a sente" contraria as abordagens atuais, desde que um dos objetivos terapêuticos em uso é de técnicas que permitam aos pacientes conviver e interagir com a dor e o sofrimento. Outro aforismo clássico da medicina, "sublata causa tollitur effectus" (retirada a causa o efeito desaparece), também é invalidado pelo próprio conceito de dor crônica.

O homem da atualidade muitas vezes ainda encara a dor com uma série de conceitos complexos, entre eles os com conotações religiosas, sentimentos de culpa e expiação, que somente dificultam a abordagem e aumentam o sofrimento. Como refere Ojugas (1) "Ante a dor reagem igualmente o homem do século XX e o das cavernas. Buscam no fundo algo sobrenatural". Daremos maior ênfase aos aspectos psicossociais em detrimento dos neurosensitivos (mediadores químicos, receptores, vias de transmissão e de modulação). O entendimento da dor não deve se limitar a sua expressão neurosensitiva, e sim também como uma mensagem emocional, uma metáfora perceptiva. Pode ser uma sensação adaptativa, um alerta precoce para proteger o corpo de lesōes teciduais, ou eventualmente ser uma má adaptação, refletindo um funcionamento patológico do sistema nervoso. De tal forma que existe a dor como uma experiência sensitiva e a dor como uma metáfora perceptiva de sofrimento, de aflição ou mágoa. Pode ser como um sistema de alarme ativado para impedir danos ao organismo. Essa nocicepção (2) é ativada somente por estímulos lesivos, atuando em receptores especializados. A nocicepção uma vez presente, após o desaparecimento do sinal de alarme, toma características motivacionais, semelhantes à fome, sede ou desejo sexual. O limiar para despertar a dor tem que ser elevado o suficiente para que a mesma seja evocada, antes que ocorra 
lesão tecidual. Esse limiar não é fixo e pode ser alterado tanto para mais como para menos, podendo ser tanto adaptativo, como mau adaptativo. Mudanças no limiar de dor e da capacidade de resposta são expressões de neuroplasticidade, que é a maneira biológica pela qual, mudanças no sistema nervoso podem modular as respostas a qualquer estímulo. Essa plasticidade caracteriza essencialmente as síndromes clínicas dolorosas (3).

MODULAÇÃO DA DOR A dor não depende somente da natureza e da intensidade do estímulo. É influenciada por fatores psicossociais e neurosensitivos. Sofre uma modulação no sistema nervoso central, e da interação entre os estímulos nociceptivos e fatores moduladores é que resulta a experiência neurosensitiva da dor. A qualidade e a quantidade da dor dependem (e varia de pessoa para pessoa) do entendimento da situação geradora da dor, experiência prévia com o desencadeador álgico, cultura, da atenção, ansiedade e capacidade da pessoa em se abstrair das sensações nóxicas (distração) e dos sentimentos de controle da dor (4) (figura 1).

DESEMPENHO DE PAPÉIS DO PACIENTE FRENTE À DOR Esse conjunto delineado anteriormente faz com que nas dores crônicas o paciente venha a assumir o papel de doente, em detrimento de outros papéis da vida cotidiana, variando segundo sua personalidade e condiçōes socioeconômicas. Essa situação leva ao afastamento das suas responsabilidades e obrigações sociais, com crescente incapacidade física e reações emocionais negativas (5).

O corpo, como espaço da doença, torna-se um conteúdo com diferentes expressōes, procurando significados, tanto para o paciente como para o terapeuta (6). Sendo o corpo um reflexo social, torna-se impossível atribuir a ele, no seu comportamento, processos exclusivamente biológicos, sendo assim simbólico de todo um processo social (7). Desse modo, a doença torna-se uma construção social, e as crenças sobre o significado e a importância da dor, e contexto onde ocorrem as emoçōes associadas, acaba afetando a sensação dolorosa (8).

Os pacientes podem se apresentar ansiosos, agressivos, deprimidos, discordarem dos diagnósticos, manifestarem efeitos adversos inexplicáveis. Por sua vez, o terapeuta pode então reagir com sentimentos negativos, enfraquecendo sua relação terapêutica com o paciente. Os questionamentos sobre as causas de que pacientes "mais ou menos semelhantes", com diagnósticos e tratamento semelhantes, possam apresentar resultados diferentes, não tem resposta no modelo biomédico convencional. Essas e outras respostas, no dizer de Cahana (9), merecem uma análise conjunta, da prática clínica, epistemológica, ontológica e fenomenológica e, para o entendimento da dor, requeremos além das habilidades biomédicas básicas, reflexōes de ordem filosófica. A filosofia do psiquismo é tão relevante quanto a reflexão da clínica médica (pesquisa pré clínica e clínica) (9).

RELAÇÕES MENTE, CORPO, DOR, PACIENTE COMO SER TOTAL OUtro aspecto aberto às discussōes reside no entendimento das relaçōes mente/corpo, de capital importância para a interpretação do complexo das dores crônicas e do seu consequente sofrimento. Ainda segundo Cahana (9), é oportuna a explicação oferecida pela hipótese da sobreposição da mente e corpo, com referência de que a sobreposição de $A$ sobre $B$ significa que não pode haver diferença em $A$ que não haja consequente correspondência em B. Se supusermos que uma pessoa esteja com dor (propriedade mental de estar e sentir dor), pelo princípio da sobreposição, alguma propriedade física da pessoa tem que ser assinalada (causar a dor). A dor sempre tem um substrato ou uma base para sobreposição. A sobreposição corpo e mente, conduz a ideia que a dor, portanto depende de um substrato neural.

A relação/cérebro mente pode ser analisada na prática com alguns exemplos. Tomamos como primeiro a estranha e trágica história de Phineas Gage, revista magistralmente, com demonstraçōes científicas atuais, por Damásio AR, em $O$ erro de Descartes, emoção, razão e o cérebro humano (10).

Trata-se da história de um jovem, de 25 anos, capataz da construção civil, inicialmente descrita de maneira detalhada pelo Dr. John Harlow que, em 1848, acompanhou o acontecimento, na qualidade de médico assistente. Em 15 de setembro de 1848 Phineas Gage, trabalhador em construção de ferrovias, admirado pelos seus colegas, pela sua dedicação, inteligência e coragem, quando manuseava uma carga de pólvora para destruir rochas, durante a explosão foi acidentado por uma barra pontiaguda de ferro, a qual penetrou pela sua hemiface esquerda, trespassando-lhe a porção retro-orbitária e o crânio, com perda de massa encefálica. Sobreviveu, sem déficits motores e da linguagem mas apresentou profundas alterações da personalidade e do caráter, com "uma linguagem obscena, irreverência, indiferença, incapacidade de tomar decisōes, com degradação da sua vida profissional e social". "Possivelmente, manifestação de lesão do lobo frontal, chamada moria". Alteração do humor e do caráter com aspecto hipomaníaco atípico, com características de expansividade, otimismo, que contrasta com seu estado mórbido, erotismo, piadas inoportunas, puerilidade, que pode ser sucedida por profunda depressão, chamado por Oppenhein de Witzelsucht $(11 ; 12)$. Hanna Damásio reconstituiu com moderna tecnologia radiológica, a partir do estudo de seu crânio, o tipo de lesão e a trajetória da barra de ferro. Concluiu por uma lesão perfurante do córtex pré-frontal bilateral (10) (figura 2). Outro exemplo é o verificado com as psicocirurgias, como a lobotomia pré-frontal, proposta por Ėgas Moniz (Prêmio Nobel de Medicina e Fisiologia, juntamente com Walter Hess, 1947) e Almeida Lima, representada no cinema de forma impecável por Jack Nicholson e Lousie Fletcher (Oscar de melhor ator e melhor atriz, respectivamente, 1976), em Um estranho no ninho, de autoria de Ken Kesey e direção de Milos Forman.

Existe uma falha para a explicação entre psiquismo e encéfalo, onde os fatos do mundo físico nunca explicam satisfatoriamente as experiências da consciência. Historicamente se discute em três eixos. Primeiro: a consciência simplesmente está lá. Duvidando disso, duvidamos da nossa existência. O que está indo na mente somente é definido e acessível para quem está experimentando o fato. Segundo: Eixo natural ou primitivo. A consciência será explicada claramente com o suporte da ciência. Há necessidade de conhecermos melhor o funcionamento do encéfalo, seu modelo computadorizado, as interaçôes comportamentais e do meio ambiente. Terceiro: combinação envolvendo uma abordagem filosófico-científica, admitindo que a 
solução esteja fora da ciência ortodoxa. Há necessidade da ciência cognitiva, de novos conceitos, modelos, técnicas experimentais, da associação entre a psicologia, neurobiologia e da filosofia, com base na experiência humana subjetiva, enfocando o ser total (9).

O entendimento das bases teóricas das doenças não é suficiente para avaliar o doente (doente não é o mesmo que doença). A abordagem deve seguir o modelo biopsicossocial (9). Também dor e sofrimento não são o mesmo. Dor é representada pelo impulso nociceptivo, lesão prévia e inflamação. Sofrimento representa o significado que a dor tem no curso da doença, a incapacidade física, social e financeira (13). Existem variadas formas de compartilhar a dor, através das atividades motoras, expressōes faciais, alteraçōes posturais, respostas autonômicas e expressões paralinguísticas (como gemer, suspirar). Este conjunto representa a linguagem da dor.

$\mathrm{Na}$ análise do impacto da dor crônica sobre o indivíduo, admite-se que haja a passagem pelos vários períodos, como descrito pela psiquiatra nascida na Suíça, Elisabeth Kübler Ross, em seu livro Sobre a morte e o morrer (14) onde, ao invés da morte, existe o sofrimento. O primeiro dos períodos identificados por Kübler Ross no processo de morte (sofrimento) é a negação, quando o paciente se recusa a aceitar que tem uma condição fatal (ou crônica). Depois se seguem a raiva, a negociação, a depressão e a aceitação de que a morte é inevitável (sofrimento). Os períodos, advertiu Kübler Ross, não se sucedem de forma ordenada e excludente, mas podem misturar-se, em particular durante o da negociação, quando o paciente pensa que caso se submeta a um determinado tratamento, ou se fizer dieta ou exercício, talvez possa reverter sua condição. O reconhecimento de que a negociação não é possível com a morte (sofrimento), frequentemente leva à quarta fase, que é a depressão. A etapa final é a aceitação, quando a pessoa reconhece sua mortalidade (seu sofrimento como tratável, não a proximidade do fim) e a proximidade do fim. Nas dores crônicas, teríamos na Fase I, comportamentos de negação, busca de tratamento, vulnerabilidade ao charlatanismo e métodos mágicos e não convencionais. Fase II, hostilidade, agressividade, litígios e abusos medicamentosos. Fase III, depressão, desespero, insônia, busca de tratamentos, não aceitação de ajuda pessoal e abuso de medicamentos. Fase IV, aceitação da incapacidade, permissão de uma abordagem realística no tratamento, podendo ser ajudado. Assim é que foram descritos diferentes comportamentos dos pacientes com dores crônicas, reconhecidos como neurose da dor, os quais devem ser considerados no processo terapêutico, relatados a seguir: incapacidade física, depressão, ansiedade, visita a múltiplos médicos, utilização abusiva de drogas, dependência física e vícios de fármacos (principalmente de narcóticos), uso de tratamentos ineficientes ou potencialmente prejudiciais, incapacidade sócio-profissional, envolvimentos judiciais, aposentadoria forçada, prejuízos financeiros e nas relações sociais, culminando algumas vezes com a rejeição familiar e frequentemente pelo sistema de saúde.

QUANTIFICAÇÃO DA DOR E COMPORTAMENTOS Existem alguns testes que buscam quantificar a dor, desde os mais simples, apenas quantificando a intensidade (unidimensionais), como as escala numérica de 0 a 10 ( $0=$ sem dor, $10=$ pior dor possível), a Escala Visual
Analógica (marcação sobre uma linha de $10 \mathrm{~cm}$, desde sem dor, até a pior dor possível), e os mais complexos, multidimensionais quantificando os aspectos sensitivos discriminativos, afetivos motivacionais e cognitivos comportamentais (Questionário de McGill) (15). São usados testes para avaliação de diferentes aspectos da personalidade e emocionais, dentre os quais temos os mais usados: de personalidade (MMPI), para a depressão (Teste de Hamilton, Teste de Becker), para qualidade de vida, e para avaliação dos mecanismos de enfrentamento.

CONCEITUALIZAÇÃO DA PERSPECTIVA BIOPSICOSSOCIAL A perSpectiva biopsicossocial é um modelo mais heurístico, quando comparada com a perspectiva reducionista e simplista, do modelo dito biomédico. O primeiro avalia a interação complexa e dinâmica entre fatores fisiológicos, psicológicos e sociais, que perpetuam e pioram as manifestaçōes clínicas.

Ajuda a explicar a diversidade da expressão da dor ou da doença, incluindo a severidade, duração e consequências psicossociais. Segundo Flor e Hermann (16), pode-se elaborar o seguinte fluxograma, explicativo para o modelo biopsicossocialda dor.

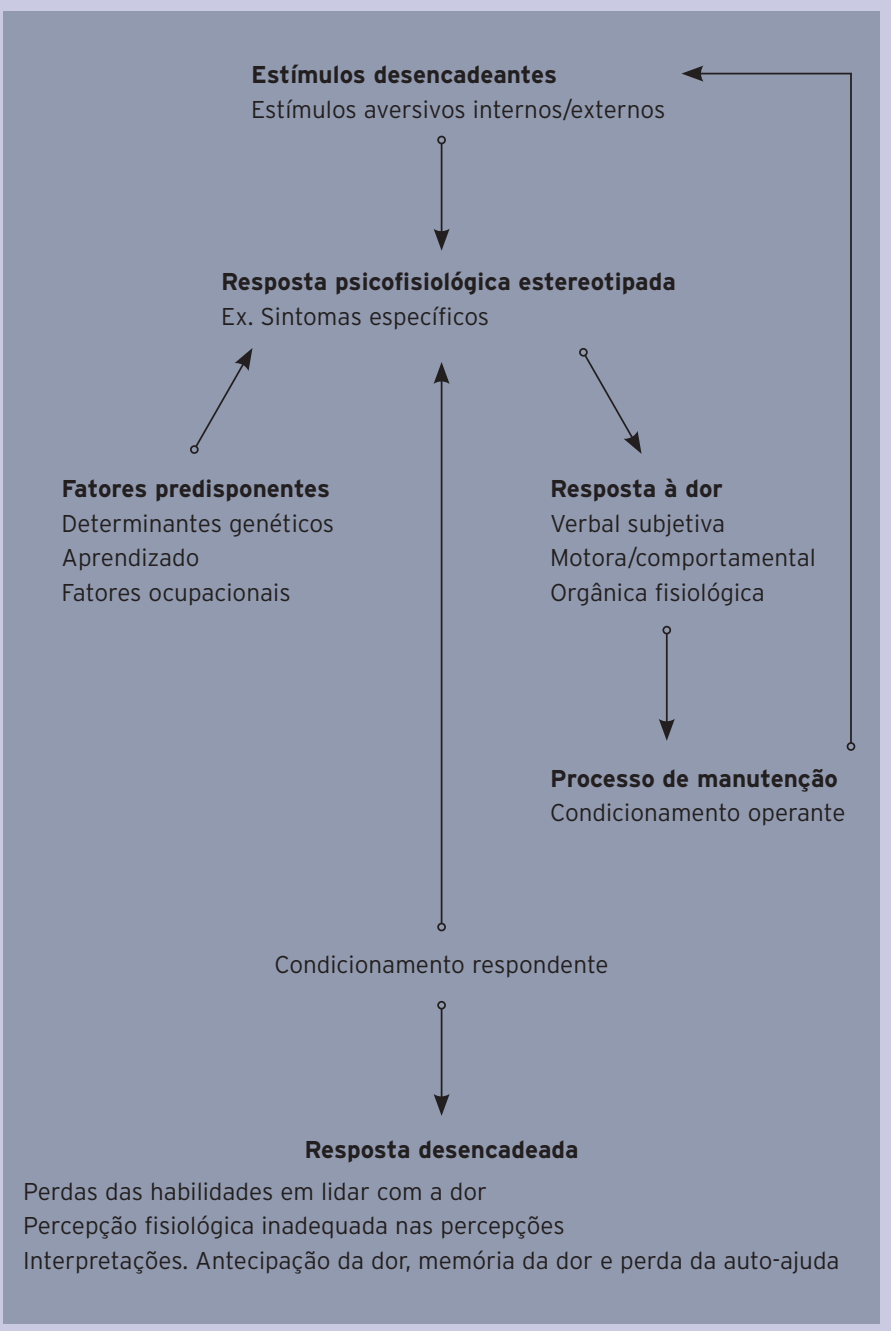



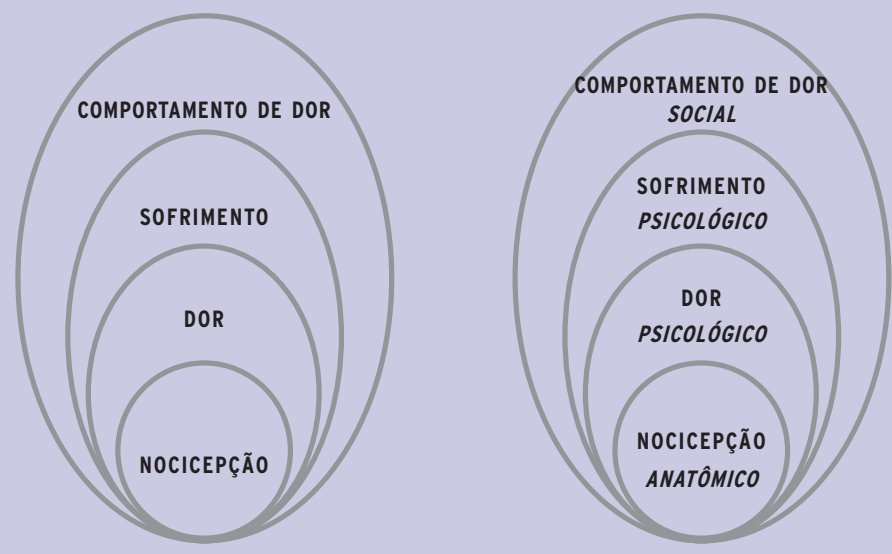

Figura 1. Interrelações entre os vários componentes da dor Figura 2. Correlações dos componentes da dor com seus equivalentes orgânicos

Nas figuras acima vemos as interrelações entre os vários componentes do ciclo da dor (figura 1), e relacionados a estes, correlações com seus equivalentes orgânicos funcionais (figura 2), estes podendo ser observados e mensurados por terceiros.

O âmbito da avaliação dos sintomas no modelo biopsicossocial, inclui uma ampla categoria de medidas física, psicológica e socioeconômica, consideradas as expressões dos sintomas, no conjunto correlacionado e interdependente, médico-espiritual- psicológico-social (17).

Transcreveremos algumas ideias e propostas relativas à conceituação e uma possível terapia das dores crônicas, resultantes da visão socioeconômica e antropológica de Porto e Garrafa, intitulada "Bioética de intervenção" (18), a meu ver pertinentes ao exposto acima no presente artigo.

O trabalho pretende "Legitimar na moralidade, na aplicação de valores éticos, uma perspectiva que envolva os aspectos sociais da produção das doenças". Seria uma colaboração criticada da bioética indicada para os países ditos periféricos, com especial atenção para o Brasil. O interessante, entre outras observações nesse trabalho, é referir como um marco teórico e conceitual, a corporeidade, sendo exatamente a dor e o prazer os indicadores da necessidade de intervenções éticas, não ficando com uma limitação de dimensão puramente fisiológica. Em qualquer sociedade o corpo é a matéria que constitui a pessoa a qual é a estruturação e o sustentáculo da vida social, funcionando a dor e o prazer como marcadores somáticos e como indicadores de intervenções. Como indicadores, refletem a satisfação de necessidades concretas, e a sua gradação reflete as condiçôes sociais e econômicas a que os sujeitos estão submetidos.

"Reconhecendo as necessidades e expectativas concretas dos seres humanos, ouvindo os ecos da dor e do prazer podemos usar instrumentos de mensuração para medir desigualdades entre sociedades". Comentam que o PIB (Produto Interno Bruto) e o IDH (Índice de Desenvolvimento Humano) levam em consideração a pobreza, expectativa de vida e o grau de conhecimento acumulado, dependentes das condições econômicas individuais.
As categorias de prazer e dor seriam utilizadas para definir o espectro das necessidades básicas da existência humana, escolha baseada na psiquiatria, psicologia, filosofia e economia. O medo, a força e a dor representariam situaçōes marcantes nas relaçôes entre explorados e exploradores, que legaliza o uso do poder, condicionando o comportamento das pessoas. Qualquer pacto social decorre, em última análise, do uso desses parâmetros que têm características sensoriais. Isso resultaria na percepção subjetiva, tendo como reflexo a dor e o sofrimento provocados pela insuficiência de recursos a que estão submetidas às pessoas de baixa renda.

Essa é, portanto, uma abordagem humanizada das necessidades sociais, colocando dor e prazer como pontos referenciais, evidenciando que o pensamento popular, "o dinheiro não traz felicidade", é acertado e que a complementação "não traz, mas compra" é uma deturpação do comportamento racional, uma perversão do capitalismo selvagem e predatório. Foge da visão fria de economistas e dos políticos com pouca ou nenhuma noção humanística, que infelizmente legislam e decidem os rumos do Brasil. Com relação à participação de alguns políticos, além do despreparo humanístico, devemos levar em conta que o povo brasileiro manifesta um traço de personalidade masoquista (prazer em sofrer e sentir dor), escolhendo personalidades sabidamente envolvidas em escândalos administrativos e financeiros, tendo também um espírito jocoso, com opções hilariantes, elegendo mesmo alguns especialistas no assunto, como comprovado pelos resultados eleitorais de uma forma geral.

Além da complexidade em si do modelo biopsicossocial existem dificuldades na metodologia para a realização de estudos epidemiológicos nas dores crônicas. Seria devido às suas diferentes prevalências, das faixas etárias abordadas, de diferenças relativas ao sexo, fatores ambientais e profissionais, de fatores ligados à equipe de saúde (diferentes áreas de atuação e profissionais, analisando a mesma afecção). Outros fatores complicadores são apontados, como os aspectos emocionais não serem ainda adequadamente valorizados nos estudos epidemiológicos, as diversidades dos desenhos dos estudos, nas etiologias, quanto às populaçóes alvos e, principalmente, da falta de uma linguagem homogênea (19).

Jaime Olavo Marquez é professor adjunto IV de neurologia (aposentado) na Faculdade de Medicina da Universidade Federal do Triângulo Mineiro, Uberaba, membro titular da Academia Brasileira de Neurologia e vice-coordenador do Departamento de Dor. Atua como membro efetivo da IASP (International Association for the Study of Pain) e coordenador do Centro de Dor, da Secretaria Municipal de Saúde de Uberaba (MG).

\section{NOTAS E REFERÊNCIAS BIBLIOGRÁFICAS}

1. Ojugas, A. C. "A dor através da história e da arte". Vol.1, p.3. Atlas Medical Publishing Ltd. 1999.

2. Nocicepção é o processo neural no qual o estímulo que pode despertar a dor é detectado pelo sistema nervoso.

3. Scholz, J.; Woolf, C. J. "Can we conquer pain?" Nature Neurosciences, Vol.5, pp.1062-1067. 2002.

4. Melzack, R. \& Wall, P.D. The challenge of pain. pp.33-41. Basic Books ed. 1983. 
5. Gatchel, R. J., 1996. Apud Hortense, P. “Escalonamento comparativo de diferentes dores nociceptivas e neuropáticas, por meio de métodos psicofísicos variados". Tese de doutorado, Escola de Enfermagem de Ribeirão Preto. USP. 2007.

6. Foucault, M. 1980. Apud Hortense, P. “Escalonamento comparativo de diferentes dores nociceptivas e neuropáticas, por meio de métodos psicofísicos variados". Tese de doutorado, Escola de Enfermagem de Ribeirão Preto. USP. 2007.

7. Ferreira, J., 1998. Apud Hortense, P. "Escalonamento comparativo de diferentes dores nociceptivas e neuropáticas, por meio de métodos psicofísicos variados". Tese de doutorado, Escola de Enfermagem de Ribeirão Preto. USP. 2007.

8. Helman CG, 1994. Apud Hortense, P. "Escalonamento comparativo de diferentes dores nociceptivas e neuropáticas, por meio de métodos psicofísicos variados". Tese de doutorado, Escola de Enfermagem de Ribeirão Preto. USP. 2007.

9. Cahana, A. "Pain and philosophy of the mind". Pain Clinical Updates. Vol.XV, no.5. July 2007.

10. Damásio, A. R. O erro de Descartes, emoção, razão e o cérebro humano. Companhia de Letras. São Paulo. 1994.

11. Ajuriaguerra, J.D. \& Hécaen, H. Le córtex cerebral, pg 41,43. Masson et Cie, França, 1960.

12. Tolosa AP, Canelas HM. Propedêutica neurológica, p.248. Sarvier. 1971.

13. Pasternak . "22nd Annual Scientific Meeting". Chicago. 2003.

14. Ross, Elisabeth Kübler. Sobre a morte e o morrer. Martins Fontes. 1969.

15. Melzack, R. "The short-form McGill Pain Questionnaire". Pain. Vol.30, no.2, pp.191-7. 1987.

16. Flor, H. \& Hermann, C. Psychosocial aspects of pain. IASP Press. 2004.

17. Zhukovsky, D. S. "22nd Annual Scientific Meeting". Chicago. 2003.

18. Porto, D. \& Garrafa, V. "Bioética de intervenção: considerações sobre a economia de mercado". Bioética, Vol.13, no.1, pp.11-123. 2005.

19. Von Korff, M.; LeResche L. Epidemiology of pain. The paths of pain 1975-2005. In: Merskey, A.; Loeser, J. D.; Dubner, R. IASP Press. 2005.

\section{BIOÉTICA, DOR E SOFRIMENTO}

\author{
José Paulo Drummond
}

"A dor não surge apenas por estimulação periférica, mas também
por uma experiência da alma, que reside no coração".
Platão

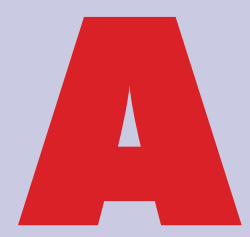

bioética originou-se das questôes concretas, relacionadas à vida, em geral, e suscitadas, recentemente, dentro das áreas médica, ecológica e social, em função dos respectivos desenvolvimentos. $\mathrm{Na}$ medicina, surgiram situaçôes existenciais que exigiam ampla abordagem, ultrapassando os limites de uma visão especializada. Entre essas questôes, podemos citar aquelas relacionadas à genética, à reprodução humana, aos transplantes de órgãos, ao aborto, à cirurgia fetal, à qualidade de vida, à reanimação, ao direito de morrer, à repressão psiquiátrica, à pesquisa etc. Em outras palavras, as decisões clínicas, em certas circunstâncias, tornaram-se tão multifacetadas que, parafraseando um dito famoso relativo à guerra e aos militares, a medicina transformou-se então em algo demasiado complexo para ser discutida apenas por médicos. A fim de se evitar um reducionismo profissional, verificou-se a necessidade de um diálogo pluridimensional e interdisciplinar, entre peritos e leigos, o que constitui a própria essência e metodologia de trabalho da bioética.

PRINCÍPIOS DA BIOÉTICA A bioética pode ser definida como "o estudo sistemático da conduta humana no âmbito das ciências da vida e da saúde, enquanto esta conduta é examinada à luz de valores e princípios morais" (1). Quem cunhou o termo, embora com um sentido distante do atual, foi um oncologista, da Universidade de Wisconsin, Van Rensselaer Potter, em seu livro Bioethics: bridge to the future (2). A bioética ultrapassa os limites dos códigos deontológicos profissionais, cujas normas morais e jurídicas, embora necessárias, transformam-se num esquema excessivamente redutor para acolher as mudanças amplas e profundas que se processam no âmbito da saúde, além de apresentarem certo viés corporativista. Neste artigo nos restringiremos à consideração dos princípios fundamentais da bioética, em sua relação com a assistência à dor e ao sofrimento. Beauchamps e Childress (3), ampliando os objetivos do Relatório Belmont sobre pesquisas, publicado em 1978 pela Comissão Nacional criada pelo Congresso norte-americano, reafirmaram o seu paradigma ético, que constituía uma referência prático-conceitual, consolidada sobre três princípios: o da beneficência, o da autonomia e o da justiça, interpretados à luz do utilitarismo. É conhecida como a tríade bioética, cuja articulação, nem sempre harmoniosa, repousa no médico (pela beneficência), no doente (pela autonomia) e na sociedade (pela justiça). O princípio de beneficência e o seu correlato de não maleficência derivam do preceito hipocrático Primum non nocere (primeiro, não causar danos), logo Bene facere (fazer o bem), e resumem-se na obrigação moral de agir em benefício do outro, seja quem for e em 